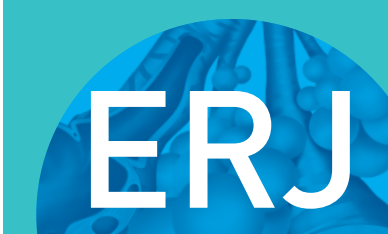

open research
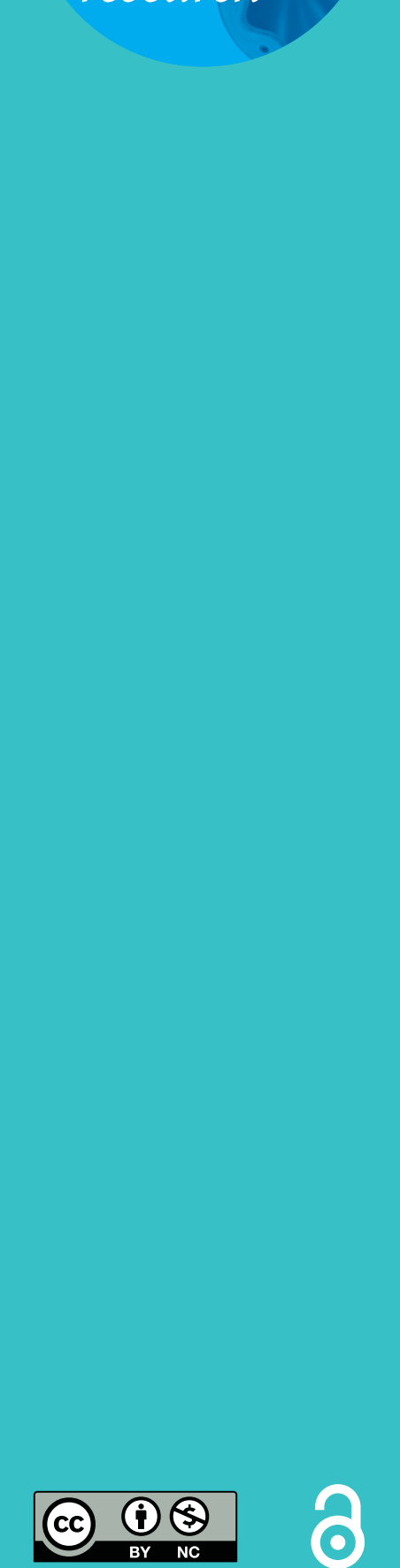

\section{Predicting and preventing hospital readmission for exacerbations of COPD}

\author{
Chia Wei Kong ${ }^{1,2}$ and Tom M.A. Wilkinson ${ }^{1,2}$
}

\section{Affiliations}

${ }^{1}$ Southampton NIHR Respiratory Biomedical Research Unit, University Hospital Southampton, Southampton, UK.

${ }^{2}$ Clinical and Experimental Sciences, Faculty of Medicine, University Hospital Southampton, Southampton, UK.

\section{Correspondence:}

Kong Chia Wei, Southampton NIHR Respiratory Biomedical Research Unit, University Hospital Southampton, Tremona Road, Southampton, S016 6YD, UK. E-mail: c.w.kongdasoton.ac.uk

ABSTRACT More than a third of patients hospitalised for acute exacerbation of COPD are readmitted to hospital within 90 days. Healthcare professionals and service providers are expected to collaboratively drive efforts to improve hospital readmission rates, which can be challenging due to the lack of clear consensus and guidelines on how best to predict and prevent readmissions. This review identifies these risk factors, highlighting the contribution of multimorbidity, frailty and poor socioeconomic status. Predictive models of readmission that address the multifactorial nature of readmissions and heterogeneity of the disease are reviewed, recognising that in an era of precision medicine, in-depth understanding of the intricate biological mechanisms that heighten the risk of COPD exacerbation and re-exacerbation is needed to derive modifiable biomarkers that can stratify accurately the highest risk groups for targeted treatment. We evaluate conventional and emerging strategies to reduce these potentially preventable readmissions. Here, early recognition of exacerbation symptoms and the delivery of prompt treatment can reduce risk of hospital admissions, while patient education can improve treatment adherence as a key component of selfmanagement strategies. Care bundles are recommended to ensure high-quality care is provided consistently, but evidence for their benefit is limited to date. The search continues for interventions which are effective, sustainable and applicable to a diverse population of patients with COPD exacerbations. Further research into mechanisms that drive exacerbation and affect recovery is crucial to improve our understanding of this complex, highly prevalent disease and to advance the development of more effective treatments.

@ERSpublications

The high prevalence of COPD hospital readmissions remains a clinical challenge worldwide. In an era of precision medicine, improved strategies including personalised interventions are required to predict and reduce these potentially preventable admissions. http://bit.ly/2w6pV2I

Cite this article as: Kong CW, Wilkinson TMA. Predicting and preventing hospital readmission for exacerbations of COPD. ERJ Open Res 2020; 6: 00325-2019 [https://doi.org/10.1183/ 23120541.00325-2019].

Copyright $\odot$ ERS 2020. This article is open access and distributed under the terms of the Creative Commons Attribution Non-Commercial Licence 4.0. 


\section{Introduction}

COPD exacerbations resulting in hospital admissions contribute to a significant clinical and economic burden worldwide [1]. COPD readmission may be defined as either rehospitalisation exclusively for acute exacerbation of COPD (AECOPD) or secondary to any cause. There is a lack of consensus when defining readmission time intervals, which may range from 30 days to 2 years [2]. Severe COPD exacerbations resulting in hospitalisation can be up to 60 times more expensive than mild or moderate exacerbations managed by primary care services [3]. In the United States, acute exacerbations of COPD leading to hospitalisations account for $\$ 13.2$ billion of the nearly $\$ 50$ billion annual direct costs for COPD [2].

A nationwide study in the US showed that 30-day readmission rate for COPD patients was 22.6\% [4]. Similarly, in the United Kingdom approximately a quarter (24\%) of patients with COPD exacerbations were readmitted at least once within 30 days of discharge, while the 90-day readmission rate was reported to be as high as $43 \%$, a substantial increase from $33 \%$ in 2008 [5]. In comparison, the European COPD audit involving $>400$ hospitals reported a 90 -day readmission rate of $35.1 \%$ [6].

Previous hospitalisation for AECOPD is a strong predictor for future readmission [7, 8] with the frequency of rehospitalisation closely linked to the number of admissions in the previous year [9]. Predictably, frequent COPD exacerbations requiring hospital admission are associated with higher mortality [10]. Although COPD was identified as the leading cause, other reasons for hospital readmissions have been described, as shown in table 1 [11].

COPD readmission is avoidable and therefore readmission rates are routinely used to assess the quality of care provided. This has led to the introduction of national incentive and penalty programmes such as the Hospital Readmissions Reduction Program (HRRP) in the US, which reduces payments to hospitals with excess readmissions [2]. In this context, predicting which patients are at risk of readmission and targeting potential interventions to prevent and reduce readmission are necessary not only to limit the adverse effects on patient outcomes, but also to alleviate their burden on healthcare costs and resources.

\section{Risk factors for readmissions \\ Comorbidities}

The majority of patients with COPD have at least one coexisting medical condition [12]. A meta-analysis reported that comorbidities were significantly higher in patients with COPD compared to non-COPD controls, and the number of comorbidities increases with age [13]. The prevalence of comorbid conditions was shown to predict both symptom severity and the number of COPD exacerbations [14].

Comorbidities including congestive heart failure, lung cancer, anxiety, obesity, depression, osteoporosis, chronic kidney disease, diabetes mellitus, hypertension and obstructive sleep apnoea were related to higher rates of readmission $[15,16]$.

Interestingly, patients with COPD with coexisting congestive heart failure and osteoporosis were found to have the greatest risk of readmission compared to other combinations of comorbidities, suggesting a differential role of concomitant comorbidities [16]. Furthermore, the number of comorbidities was shown to be related to a stepwise increase in the rate of readmissions $[16,17]$. It was suggested that the risk of readmission increased by $47 \%$ by every single unit of increase in comorbidities [17].

Anxiety and depression frequently coexist and are highly prevalent among patients with COPD, although commonly unrecognised and undertreated $[9,18,19]$. Depression was associated with increased risk of both short-term (30-day and 90-day) and 1-year readmission [18], while anxiety was independently associated with very frequent readmissions [9]. Despite the high frequency of coexisting depression, at present there is insufficient evidence to ascertain the efficacy of antidepressants in reducing readmission rates [20].

\section{TABLE 110 leading reasons for COPD readmissions following index COPD admission [11]}

\section{COPD}

Respiratory failure

Pneumonia

Congestive heart failure

Asthma

Septicaemia

Cardiac dysrhythmias

Fluid and electrolyte disorders

Intestinal infection

Nonspecific chest pain 
Future treatment strategies should include the focus of addressing comorbid conditions given their prevalence, complexity and potential impact on hospital readmissions. It is likely that only a holistic approach that considers the breadth of multimorbidity will significantly impact on the rate and burden of readmission.

\section{Physical activity, frailty and sarcopenia}

Patients with COPD who reported higher levels of usual physical activity had a significantly lower risk of readmission to hospital [21]. In another study, patients who were non-ambulatory within $24 \mathrm{~h}$ of discharge were twice as likely to be readmitted to hospital within 30 days compared to patients who were mobile [22]. Low levels of physical activity were evident during and after hospitalisation for AECOPD, which may result from multiple causes [23]. A slower recovery rate in physical activity was demonstrated even up to 1 year following the index admission [23]. As expected, the readmission rate was higher in patients with lower physical activity at 1 month after hospital discharge [23].

Frailty is a multidimensional syndrome reflecting diminished physiological reserves increasing the risk of adverse outcomes in patients, including those with COPD [24]. Frailty is defined by the Fried phenotype model based on the presence of three or more of the following criteria: unintentional weight loss (10 lbs in the past year), self-reported exhaustion, weakness (grip strength), slow walking speed and low physical activity [25].

The 4-m gait speed (4MGS), a surrogate marker of physical activity and frailty, can independently predict the risk of COPD readmissions, where slower measurements were associated with significantly higher all-cause readmissions at 90 days and shorter time to readmission [26]. The Reported Edmonton Frail Scale (REFS) assessing multidimensional frailty may be useful to stratify patients with AECOPD who are at risk of readmission [27]. In this study, hospital readmission was five times higher in patients with severe frailty (highest REFS scores) compared to non-frail patients (lowest REFS scores).

Future readmissions may be predicted by assessing acutely unwell patients hospitalised with COPD exacerbations for skeletal muscle dysfunction indicated by smaller quadriceps muscle mass (measured using ultrasound) [28]. Targeting this vulnerable subgroup of patients for risk stratification may improve outcomes through personalised disease management.

\section{Lung function}

Disease severity in COPD is routinely assessed using the Global Initiative for Chronic Obstructive Lung Disease (GOLD) staging criteria, which takes into account the degree of airflow limitation (forced expiratory volume in $\left.1 \mathrm{~s}\left(\mathrm{FEV}_{1}\right)\right)$, symptoms and history of exacerbations [29]. The number of hospitalisations per year was positively correlated to the severity of COPD using the GOLD classification [30] with $>85 \%$ of admissions having GOLD stage 3 or 4 disease [17]. In addition, lower oxygen tension appears to be an independent risk factor for COPD readmission in patients with low percentage predicted $\mathrm{FEV}_{1}$ [21]. While this approach has some validity ( $\mathrm{FEV}_{1}$ has been significantly associated with readmissions in various studies [21, 31,32] and frequent rehospitalisation was very common among patients with severe dyspnoea [33]), it has limited predictive value due to inconsistency of study findings.

These measures of COPD severity may be surrogate measures of the poor functional status and frailty of these patients rather than independent factors. This is an important distinction, as it may be feasible to improve functional capacity through exercise and nutritional interventions and thus reduce risk of readmission without affecting $\mathrm{FEV}_{1}$.

\section{Nutritional status and body mass index}

Malnutrition (International Classification of Disease-9 Clinical Modification codes 260, 261, 262, 263.0, 263.1263 .9 ) was associated with a higher risk of 30-day readmission, whereas obesity was found to be a protective factor [34]. Low body mass index (BMI) and weight loss during hospitalisation for AECOPD was associated with earlier readmission [35]. This was also observed in another study where high BMI was associated with lower risk of first AECOPD admission and subsequent readmission, again supporting the "obesity paradox" [36]. Patients hospitalised for COPD exacerbations often have dysregulated energy balance secondary to reduced dietary intake and increased resting energy expenditure which, if left uncontrolled, may lead to further metabolic derangements, weight loss and heightened systemic inflammation [37].

\section{Social factors}

A meta-analysis demonstrated significant inverse correlations between socioeconomic status and COPD outcomes including secondary healthcare utilisation [38]. Other studies revealed that patients residing in the 
lowest income areas and home healthcare discharges were more likely to be readmitted to hospital [15, 34]. In addition, marital status was linked to readmission rates, highlighting the potential influence of social connection and domestic support on recurrent hospitalisations [17]. Individuals who were single had a $18 \%$ higher readmission rate compared to patients with a supporting partner [17]. KeATING et al. [39] reported that difficulties with transportation, including inability to travel independently led to patients failing to attend or complete pulmonary rehabilitation, which may impact disease management. These studies suggest that social isolation has significant adverse effects on the ability of patients to manage their disease; social interventions which are now advocated in primary care may have an impact in this vulnerable patient population.

\section{Hypercapnic respiratory failure}

$\mathrm{Up}$ to a quarter of COPD exacerbations are complicated by acute hypercapnic respiratory failure (AHRF) [5, 40]. Patients with AHRF treated with noninvasive ventilation (NIV) have a high risk of readmission within 12 months of hospital discharge [41]. Up to $80 \%$ of patients were readmitted with respiratory diagnoses and nearly half of discharged patients died within 1 year [41]. Although NIV is well established as the gold-standard treatment for AHRF in COPD exacerbations, treatment failure leading to invasive ventilation or death has been reported to be as high as 20-30\% [42]. Once initiated, directly discontinuing NIV upon resolution of respiratory acidosis has been demonstrated to be no less inferior in relapse $[43,44]$ and 6-month readmission rates [44] compared to the conventional approach of stepwise withdrawal.

\section{Biological mechanisms and biomarkers}

Early recognition of exacerbation symptoms and prompt treatment was associated with faster recovery and fewer hospitalisations [45]. Frequent exacerbations are associated with increased number of hospital admissions and longer inpatient stay [46]. Further understanding of disease processes driving frequent exacerbations is needed to address the enigma of repeated hospitalisations.

HURST et al. [47] demonstrated that a history of exacerbations was the most important determinant of frequent exacerbations in all GOLD stages of disease severity [47]. A distinct subgroup of patients who were particularly prone to frequent exacerbations independent of disease severity was described, which may be targeted for specific interventions to prevent both hospital admissions and readmissions. Beyond history the question remains whether there are other markers of future exacerbation and hence readmission risk.

PERERA et al. [48] showed that higher serum CRP concentration 14 days after an index exacerbation was associated with recurrent exacerbations within 50 days. In another study, high C-reactive protein (CRP) levels in patients with peripheral blood eosinophils $\leqslant 2 \%$ were associated with increased risk of hospital readmission [49]. In a subgroup of hospitalised COPD patients with elevated CRP, the rate of subsequent hospital readmission was reduced following treatment with low-dose azithromycin over 3 months [50]. Measuring the systemic inflammatory response by utilising CRP concentration may be a useful marker to predict the outcome of COPD exacerbations and allow the identification of patients at risk of recurrent exacerbations for specific treatment and follow-up. However, this approach requires careful consideration of other mechanisms, including comorbidities, contributing to elevated CRP in COPD patients. In addition, future translational research will need to focus on accurately defining the threshold of CRP as a sensitive biomarker for readmission.

Respiratory viruses including influenza, human rhinovirus and respiratory syncytial virus frequently precipitate COPD exacerbations. Interestingly, only coryzal symptoms were found to be significantly associated with recurrent exacerbations when compared to other exacerbation symptoms [48]. An epidemiological study concluded that frequent exacerbators were more likely to acquire the common cold compared to COPD patients with infrequent exacerbations, further strengthening the association between viral respiratory infections and recurrent airway exacerbations [51]. Furthermore, viral infections may lead to changes in the lung microbiota and alterations in host immune responses, thereby increasing susceptibility to bacterial infections [52]. Co-infection with viruses and bacteria was associated with a higher risk of hospital readmission at 60 days compared to bacterial or viral infection alone [53]. Influenza vaccination, despite being advocated internationally and attaining high levels of seroprotection in COPD patients (thereby reducing their risk of exacerbations and hospitalisations) was associated with inconsistent rates of uptake worldwide [54]. Interferon (IFN)- $\beta$, a vital immune regulator, appears to be promising in modulating viral infections by reducing the percentage of nucleoprotein 1 positive cells when administered prophylactically [55]. As an emerging treatment, inhaled IFN- $\beta$ may potentially lessen secondary healthcare burden, especially during viral seasons where effective antiviral agents are lacking. 
Bacterial colonisation of the lower airways is a common finding in clinically stable patients with COPD [56] and is associated with higher exacerbation frequency [57]. The stability of the lung microbiome in COPD was described by modelling longitudinal exacerbations as a Markov chain [58]. We showed that frequent exacerbators had higher microbiome variability, while non-typeable Haemophilus influenzae (NTHI)-positive bacterial exacerbations were most likely to repeat a subsequent NTHI-positive exacerbation [58]. The presence of airway bacterial dysbiosis appears clinically relevant in the context of exacerbation recovery, highlighting a need for further research to investigate biological mechanisms and potential treatment strategies, including the suppression of NTHI carriage in COPD.

IgG deficiency has been implicated in recurrent respiratory infections $[59,60]$ and can affect one in five patients with COPD [61]. This subgroup of patients is therefore more vulnerable to frequent exacerbations [61] and serum total IgG level $<7.0 \mathrm{~g} \cdot \mathrm{L}^{-1}$ measured during admission for AECOPD was associated with $41 \%$ increased risk of rehospitalisation [62]. More importantly, this highly susceptible patient population may potentially benefit from IgG replacement therapy if benefits are derived from controlled clinical trials.

Activated eosinophils found in induced sputum and lung samples were significantly higher in patients with COPD than in healthy controls, suggesting a role of eosinophilic inflammation in COPD [63]. Increased eosinophil count on admission can predict a more than threefold increase in 12-month readmission for COPD and a shorter time to first COPD-related readmission [64]. These findings were echoed by another study in which blood eosinophilia was associated with worse COPD readmission outcomes [65]. Various studies have demonstrated that higher eosinophil levels in COPD have a greater corticosteroid response leading to reduced exacerbation frequency, which may allow targeted treatment in this phenotypic group $[66,67]$.

\section{Predictive models of readmission}

Predictive models of readmission can assist clinicians in developing treatment strategies specifically targeting those at high risk of hospitalisation and readmissions. Some of the earlier COPD-specific predictive models including ADO (age, dyspnoea, airflow obstruction), BODEX (BMI, airflow obstruction, dyspnoea, exacerbation) and DOSE (dyspnoea, obstruction, smoking, exacerbation) (table 2) were only able to provide modest prediction for hospital readmissions, as all these scores were originally developed to predict mortality [72]. The LACE (length of hospital stay, acuity of admission, comorbidities, emergency department use) index is a generic predictive tool for readmissions with suboptimal discriminative ability to predict 30-day readmission following hospitalisation for COPD exacerbation [73], highlighting the potential influence of population and disease heterogeneity and the need to move away from a one-size-fits-all approach.

The PEARL (previous admissions, extended Medical Research Council dyspnoea score, age, right-sided heart failure, left-sided heart failure) score was first developed and validated in the UK to accurately stratify patients' risk of readmission and death [72]. The PEARL prognostic score covers five indices [72] (table 3); patients are categorised according to low risk (0-1), intermediate risk (2-4) and high risk (5-9) of readmission or death within 90 days. PEARL was shown to be easily applied at the bedside and although its c-statistic was only $\sim 0.7$, this was superior to other pre-existing predictive models including ADO, BODEX, CODEX (comorbidity, obstruction, dyspnoea, previous severe exacerbations), DOSE and LACE [72]. The development of novel computed tomography imaging techniques can improve the detection and measurement of key morphological features in COPD, including functional gas trapping and bronchial wall thickening, which are needed to better stratify disease phenotypes and may be utilised to enhance multidimensional prognostic tools when combined with clinical and spirometric parameters [74].

\begin{tabular}{|c|c|c|c|}
\hline ADO & BODEX & DOSE & LACE \\
\hline $\begin{array}{c}\mathrm{FEV}_{1} \% \text { pred } \\
\text { mMRC dyspnoea } \\
\text { scale } \\
\text { Age }\end{array}$ & $\begin{array}{c}\text { FEV }_{1} \% \text { pred } \\
\text { Number of exacerbations } \\
\text { per year } \\
\text { mMRC dyspnoea scale } \\
\text { BMI }\end{array}$ & $\begin{array}{c}\text { mMRC dyspnoea scale } \\
\text { FEV }_{1} \% \text { pred } \\
\text { Smoking status } \\
\text { Number of exacerbations } \\
\text { per year }\end{array}$ & $\begin{array}{c}\text { Length of stay } \\
\text { Acuity of admission } \\
\text { Comorbidities } \\
\text { Emergency department } \\
\text { visits }\end{array}$ \\
\hline
\end{tabular}

ADO: age, dyspnoea, airflow obstruction; BODEX: body mass index (BMI), airflow obstruction, dyspnoea, exacerbation; DOSE: dyspnoea, obstruction, smoking, exacerbation; LACE: length of hospital stay, acuity of admission, comorbidities, emergency department use; $\mathrm{FEV}_{1}$ : forced expiratory volume in $1 \mathrm{~s} ; \%$ pred: \% predicted; mMRC: modified Medical Research Council. 
TABLE 3 PEARL (previous admissions, extended Medical Research Council (eMRC) dyspnoea score, age, right-sided heart failure, left-sided heart failure) indices and weighting [68]

Weighting

Previous admissions $(\geqslant 2)$

\section{Readmission in the context of treatment and processes of care}

\section{Antibiotics}

An observational study showed that patients treated with antibiotics in the first 2 days of hospital admission had lower rates of readmission for acute exacerbations [75]. Although the readmission rate for Clostridium difficile infections was higher in the treated group, this was only a slight increase in percentage $(0.19 \%$ versus $0.09 \%)$ [75]. Similarly, the addition of antibiotics to patients on systemic corticosteroids for AECOPD was associated with a $13 \%$ reduction in the risk of 30-day readmission in addition to a $40 \%$ reduction in the risk of in-hospital mortality [76].

As a promising secondary prevention strategy, azithromycin initiated at the onset of severe AECOPD and continued for 3 months was demonstrated to be well tolerated and may potentially prevent relapse and therefore reduce readmissions [77]. Additionally, azithromycin may reduce viral load by upregulating IFN levels, supporting its potential role as a prophylactic and therapeutic agent in combating viral infections [78]. In an era of rising antibiotic resistance among common respiratory pathogens, there is increasing emphasis on accurately identifying bacteria-associated exacerbations, including the use of biomarkers such as sputum interleukin-1 $\beta$ [79].

\section{Systemic corticosteroids}

Systemic corticosteroids used to treat AECOPD reduced relapse in addition to improving lung function and decreasing inpatient length of stay [80]. Overall, there was no additional benefit with regard to treatment failure of parenteral compared to oral administration of corticosteroid [80]. In addition, there was no difference in outcomes for relapse and re-exacerbation time between shorter ( $\leqslant 7$ days) and longer ( $>7$ days) treatment regimens following AECOPD admission [81]. A 5-day course of $40 \mathrm{mg}$ prednisone was likely to be sufficient, since this shorter duration of treatment was noninferior compared to a 14-day course with regard to re-exacerbation rate within 6 months of follow-up [82]. Peripheral blood eosinophil may be used as a biomarker-directed strategy in stratifying the use of oral corticosteroids during AECOPD, as patients with eosinophilia showed faster recovery with prednisolone while higher treatment failures were observed in the control group [83].

\section{Inhaled therapy}

Inhaled corticosteroids (ICS; long-acting bronchodilators) and long-acting $\beta$-agonists (LABA) remain the backbone treatment of stable COPD. Patients who received ICS after hospitalisation had $24 \%$ fewer readmissions at 1-year follow-up [84]. The lower risk of readmissions observed is not surprising given the reduction of moderate and severe COPD exacerbations observed with the use of ICS [85]. The combination of ICS and LABA resulted in a greater reduction in risk of readmissions (41\%) when compared to either ICS or LABA alone [86]. Although the benefits of ICS are evident, the risk of pneumonia as an adverse event was significantly higher in this group and treatment should only be considered in selected patients [85].

\section{Treatment adherence}

Patients on maintenance COPD treatment prior to hospitalisation were $51 \%$ less likely to have an all-cause readmission [87]. Adherence to inhaled COPD treatment was associated with fewer hospital admissions in patients with moderate-to-severe COPD [88]. Improved adherence to inhalers by utilising a targeted pharmacy programme ensuring patients are discharged with their inpatient inhalers showed a reduction in 30-day and 60-day readmissions [89]. Understandably, adherence was related to the dosing frequency of prescribed inhalers with once-daily dosing having the highest adherence levels [90]. Establishing patients 
on the appropriate treatment regimen for their chronic disease and maximising adherence appears to be vital in reducing readmissions.

\section{Processes of care}

COPD admission prior to diagnosis in primary care was related to higher risk of both first AECOPD admission and readmission, suggesting that earlier diagnosis in primary care and early management of disease may reduce the risk of COPD admission and readmissions [36].

Higher rates of readmissions were related to lower patient experience measures in all domains including communication and discharge information [91], indicating that information provision has a positive impact. Patient education may increase self-awareness and empower patients to make informed choices about their health and improve compliance with treatment resulting in better control of symptoms and disease burden.

One study reported that short inpatient episodes shortened the interval to readmission with 1 week's duration of inpatient treatment resulting in the longest interval [92]. However, the interval to readmission became shorter when the duration of inpatient treatment extended beyond 7 days, possibly reflecting underlying disease severity, the impact of comorbidities and need for social care intervention [92].

\section{Specific interventions for COPD}

\section{Pulmonary rehabilitation}

Self-reported engagement in any level of moderate-to-vigorous physical activity in COPD patients was associated with lower 30-day readmission risk [93]. Neuromuscular electrical simulation to counteract physical inactivity and improve functional exercise capacity by enhancing peripheral muscle function and improving breathlessness [94,95] seems promising. This approach, which involves passive training of specific locomotor muscle groups may be particularly useful in the patients who are most unwell with incapacitating symptom burden.

Pulmonary rehabilitation, a key intervention in the management of COPD is defined as a comprehensive intervention based on a thorough patient assessment followed by patient-tailored therapies that include, but are not limited to, exercise training, education and behaviour change [96].

A Cochrane review showed that pulmonary rehabilitation following COPD exacerbation was associated with a significant reduction in the risk of hospital readmissions observed over a 3-18-month period [97]. However, early rehabilitation intervention initiated within $48 \mathrm{~h}$ of acute admission for AECOPD did not reduce the risk of readmissions nor improve physical function [98]. Early inpatient rehabilitation may impact on health behaviour given the lower uptake of outpatient pulmonary rehabilitation in the intervention group [98]. These findings suggest careful consideration when delivering rehabilitation during the early phase of an illness given the lack of positive outcomes. In response to increasing demands to improve capacity and compliance, a novel online pulmonary rehabilitation programme was demonstrated to be noninferior to standard practice and may be used to overcome the barriers to accessibility often associated with the traditional face-to-face structured programme [99].

\section{Nutritional supplementation}

The Cochrane review by FERREIRA et al. [100] suggested that nutritional support significantly improved weight gain and should be considered as part of the holistic management of malnourished patients with COPD. The use of oral nutritional supplementation in patients hospitalised for AECOPD was associated with reduced 30-day readmission rates, possibly by reversing the disturbed energy balance in the acute phase of the illness [101]. Improved inspiratory muscle strength and physical activity was demonstrated when specific nutritional supplementation was combined with exercise training in COPD patients [102]. The cost-effectiveness of nutritional intervention and its role in specific metabolic phenotypes needs to be further explored in future trials.

\section{Domiciliary NIV and oxygen therapy}

The Home Oxygen Therapy Home Mechanical Ventilation (HOT-HMV) trial investigated the effect of adding home NIV to home oxygen in patients with persistent hypercapnia following AECOPD requiring NIV in hospital [103]. Patients were recruited if they had persistently raised arterial carbon dioxide tension $\geqslant 2$ weeks after resolution of AHRF [103]. The addition of NIV to home oxygen resulted in a $17 \%$ absolute risk reduction in readmissions, prolonged time to readmission and death within 12 months [103]. The median admission-free survival time was 4.3 months in the treatment arm compared to 1.4 months for those in the control group [103]. The development of novel automated devices for optimal maintenance of target oxygen saturation measured by pulse oximetry and oxygen weaning may minimise 
the risk of hypercapnia and AHRF associated with inadequate titration and regulation of oxygen therapy $[104,105]$.

Despite inadequate clinical evidence, short-burst oxygen therapy (SBOT) is still incorrectly and widely advocated for COPD patients with dyspnoea $[106,107]$. The use of SBOT following AECOPD admission did not improve symptom control, readmission rates or time to readmission [106]. Long-term oxygen therapy (LTOT) is proven to improve survival in patients with severe hypoxaemia; however, its role in preventing readmissions is less clear [108-111].

\section{Palliative care}

The management of physical and psychosocial burden in COPD can often be challenging, implicated by unpredictable disease trajectories, difficult prognostication and the underutilisation of palliative care services [112]. Community-based palliative care provision in COPD was associated with lower 30-day readmission rates [113], while no benefit was observed in another study involving care delivered by hospital-based specialised palliative care teams [114]. Early integration of palliative care into COPD care models endorsing modern multidisciplinary approaches appears to be essential, but barriers to accessible, open and effective palliative care conversations between patients and healthcare professionals need to be addressed beforehand [115].

\section{Clinical service strategies and care bundles \\ Self-management plans}

Self-management empowers patients to modify behaviour, acquire knowledge about disease management and develop practical skills [116]. Self-management interventions in COPD may vary widely in content and delivery methods [117].

A health coaching intervention which centred on self-management abilities supported by healthcare professionals reduced rehospitalisation at 1, 3 and 6 months compared to standard care appears to be feasible and replicable to address short-term readmissions [118]. Similarly, other self-management interventions can significantly impact on rates of hospital admission and healthcare utilisation [119, 120]. In contrast, although perceived health status was improved, patients who received education on self-management of COPD were readmitted sooner than those receiving standard care [121]. In another study, higher readmission rates were observed following the implementation of a 3-month programme which focused on transitional care and self-management support [122]. Increased awareness and vigilance about early recognition of exacerbation symptoms and poor primary care accessibility may have been implicated in the increased use of acute care services [121, 122].

Further evidence is required to derive recommendations on form and contents of self-management programmes in COPD owing to the lack of uniformity in interventions, patient population and outcome measures [117]. Furthermore, self-management in COPD usually requires significant engagement in a range of activities, which can be challenging for patients [123]. Furthermore, the ability to self-manage may be impacted by a wide range of physical, psychological and social influences [123].

\section{COPD care plans and discharge bundles}

COPD discharge bundles consist of evidence-based practices to optimise patient outcomes following hospital discharge for AECOPD. A meta-analysis showed that discharge care bundles for patients with COPD can result in significantly reduced hospital readmissions [124]. However, COPD discharge care bundles may vary in their individual components and elements. The British Thoracic Society includes five high-impact actions in their discharge care bundle (table 4).

A comprehensive care designed focusing on appropriate diagnostic testing, management of comorbid conditions, palliative care discussions and outpatient follow-up arrangements demonstrated $16 \%$ reduction in all-cause 30-day readmission, reduced 30-day mortality rate and significant improvement of AECOPD-specific readmissions at 90 days [126]. In contrast, readmission rates were unchanged following the implementation of

\section{TABLE 4 Components of the British Thoracic Society (BTS) COPD discharge care bundle [125]}

1. Review patient's medications and demonstrate use of inhalers

2. Provide written self-management plan and emergency drug pack

3. Assess and offer referral for smoking cessation

4. Assess for suitability of pulmonary rehabilitation

5. Arrange follow-up call within $72 \mathrm{~h}$ of discharge 
COPD care bundles in a multisite study, although a reduction in subsequent emergency department attendances was observed [127]. Inconsistent care delivery processes and low intervention uptake reflect "real world" challenges for effective implementation of multifaceted care bundles [127].

The identification of local system-level failures and unmet patient needs including deficient inhaler regimen at discharge and suboptimal follow-up led to the delivery of a COPD care bundle consisting of appropriate inhaler regimen, 30-day inhaler supply, personalised inhaler education, standardised discharge instructions and follow-up within 15 days [128]. Implementation of this improvement strategy successfully reduced COPD all-cause 30-day readmissions from $22.7 \%$ to $14.7 \%$ [128]. Care delivery failures and unmet patient needs are modifiable risks for readmissions which will vary in each healthcare setting and should be assessed when designing COPD care bundles.

\section{Hospital at home}

Hospital at home schemes allow patients with COPD exacerbations which would normally require inpatient care to be managed at home by healthcare professionals with the aim of reducing the burden of hospital admission. A study investigating home hospitalisation in Barcelona demonstrated not only lower rates of short-term relapses requiring emergency admissions, but also greater patient satisfaction and quality of life, and lower average overall healthcare cost per patient compared to conventional care in hospital [129]. A Cochrane review by JEPPESEN et al. [130] showed that inpatient readmission rates were significantly lower in favour of hospital at home schemes.

\section{Conclusion}

The high and rising COPD readmissions rate worldwide remains a conundrum for healthcare professionals and service providers with important implications for patients. Patients with multiple comorbidities, prior hospital admission, higher frailty indices, poor nutritional and low socioeconomic status appear to be at the highest risk of readmission. Patients are readmitted for various medical problems other than COPD exacerbation including pneumonia and cardiac failure, highlighting the need of careful management and follow-up of multimorbidity.

COPD is a heterogeneous disease and biomarkers are needed to accurately detect disease activity, identify disease phenotypes and guide clinical care and prognosis. The complex relationship between airway inflammation, the innate immune system, micro-organisms and the environment play a key role in COPD exacerbations and further understanding of biological mechanisms that commence and sustain exacerbations is required to improve the precision of biomarkers. Socioeconomic factors may be more challenging to address and will benefit from early stratification and management.

Quantifying the risk of re-exacerbation on an individual patient basis allows clinicians and services to target therapy and healthcare resources to the greatest need. Tools do exist and the PEARL score is a simple and effective prognostic aid that can be used easily to stratify the risk of readmission in the COPD population. Future predictive scores will also need to address the multifactorial and comorbid nature of readmissions.

Readmission occurs due to both a heightened risk of re-exacerbation and a loss of function and resilience driven by an index event. Future strategies to prevent readmission will need to focus on addressing risk factors including comorbidities and frailty, supporting patient education and maximising treatment compliance. Studies suggest shorter courses of antibiotics and corticosteroids are sufficient in the event of acute exacerbation, which may also improve treatment adherence, while biomarker driven approaches to prescription may limit side-effects and the threat of antimicrobial resistance. Post-discharge interventions such as pulmonary rehabilitation programmes, as well as domiciliary NIV for patients with persistent hypercapnia have been shown to improve the rates of COPD readmission and should be offered to patients at risk.

Monitoring individual patients and intervening early has been shown to reduce hospitalisations, promote faster recovery and improve health-related quality of life. Supporting patient self-management may be used as a key intervention as this will empower patients to better manage their disease more independently and help mitigate the strain on secondary care.

The use of multifaceted care bundles can help ensure that standards and quality of care are maintained by ensuring that all available evidence-based interventions are in place and by overcoming inconsistencies in clinical decision-making. However, there is lack of consensus on which individual components are most effective and implementation of care bundles needs to consider the generalisability of interventions owing to the diversity in target populations and accessible resources. In order to address the clinical challenge of COPD readmissions, new research is needed, and better treatment regimens are required that address the underlying disease mechanisms which drive exacerbation, admission and readmission. While this is awaited, the application of optimal standards of care, including effective, personalised interventions is a must for all healthcare providers and clinicians caring for patients with COPD. 
Conflict of interest: C.W. Kong has nothing to disclose. T.M.A. Wilkinson reports grants and personal fees from GSK and AZ; grants and personal fees from $\mathrm{MMH}$, of which he is a company director; personal fees and nonfinancial support from BI; grants and personal fees from Synairgen, during the conduct of the study; and personal fees from MMH outside the submitted work.

\section{References}

1 Wedzicha JA, Wilkinson T. Impact of chronic obstructive pulmonary disease exacerbations on patients and payers. Proc Am Thorac Soc 2006; 3: 218-221.

2 Shah T, Press VG, Huisingh-Scheetz M, et al. COPD readmissions: addressing COPD in the era of value-based health care. Chest 2016; 150: 916-926.

3 Andersson F, Borg S, Jansson SA, et al. The costs of exacerbations in chronic obstructive pulmonary disease (COPD). Respir Med 2002; 96: 700-708.

4 Jencks SF, Williams MV, Coleman EA. Rehospitalizations among patients in the Medicare fee-for-service program. N Engl J Med 2009; 360: 1418-1428.

5 Stone RA, Holzhauer-Barrie J, Lowe D, et al. COPD: Who Cares When it Matters Most? National Chronic Obstructive Pulmonary Disease (COPD) Audit Programme: Outcomes from the Clinical Audit of COPD Exacerbations Admitted to Acute Units in England 2014. National Supplementary Report. London, Royal College of Physicians, 2017.

6 Hartl S, Lopez-Campos JL, Pozo-Rodriguez F, et al. Risk of death and readmission of hospital-admitted COPD exacerbations: European COPD audit. Eur Respir J 2016; 47: 113-121.

7 Connolly MJ, Lowe D, Anstey $\mathrm{K}$, et al. Admissions to hospital with exacerbations of chronic obstructive pulmonary disease: effect of age related factors and service organisation. Thorax 2006; 61: 843-848.

8 Baker CL, Zou KH, Su J. Risk assessment of readmissions following an initial COPD-related hospitalization. Int Chron Obstruct Pulmon Dis 2013; 8: 551-559.

9 Tsui MS, Lun FCT, Cheng LSL, et al. Risk factors for hospital readmission for COPD after implementation of the GOLD guidelines. Int J Tuberc Lung Dis 2016; 20: 396-401.

10 Soler-Cataluña JJ, Martínez-García MÄ, Román Sánchez P, et al. Severe acute exacerbations and mortality in patients with chronic obstructive pulmonary disease. Thorax 2005; 60: 925-931.

11 Shah T, Churpek MM, Coca Perraillon M. Understanding why patients with COPD get readmitted: a large national study to delineate the Medicare population for the readmissions penalty expansion. Chest 2015; 147: $1219-1226$.

12 Anecchino C, Rossi E, Fanizza C, et al. Prevalence of chronic obstructive pulmonary disease and pattern of comorbidities in a general population. Int J Chron Obstruct Pulmon Dis 2007; 2: 567-574.

13 Yin HL, Yin SQ, Lin QY, et al. Prevalence of comorbidities in chronic obstructive pulmonary disease patients: a meta-analysis. Medicine 2017; 96: e6836.

14 Fumagalli G, Fabiani F, Forte S, et al. INDACO project: COPD and link between comorbidities, lung function and inhalation therapy. Multidiscip Respir Med 2015; 10: 4.

15 Jiang X, Xiao H, Segal R, et al. Trends in readmission rates, hospital charges, and mortality for patients with chronic obstructive pulmonary disease (COPD) in Florida from 2009 to 2014. Clin Ther 2018; 40: 613-626.

16 Sharif R, Parekh T, Kuo Y-F, et al. Predictors of early readmission among patients hospitalized with chronic obstructive pulmonary disease. Chest 2014; 145: 420A

17 Wong AWM, Gan WQ, Burns J, et al. Acute exacerbation of chronic obstructive pulmonary disease: influence of social factors in determining length of hospital stay and readmission rates. Can Respir J 2008; 15: 361-364.

18 Iyer AS, Bhatt SP, Garner JJ, et al. Depression is associated with readmission for acute exacerbation of chronic obstructive pulmonary disease. Ann Am Thorac Soc 2016; 13: 197-203.

19 Light RW, Merrill EJ, Despars JA, et al. Prevalence of depression and anxiety in patients with COPD. Relationship to functional capacity. Chest 1985; 87: 35-38.

20 Pollock J, van Agteren J, Carson-Chahhoud K. Pharmacological interventions for the treatment of anxiety disorders in chronic obstructive pulmonary disease. Cochrane Database Syst Rev 2018; 12: CD012346.

21 Garcia-Aymerich J, Farrero E, Félez M, et al. Risk factors of readmission to hospital for a COPD exacerbation a prospective study. Thorax 2003; 58: 100-105.

22 Nguyen HQ, Rondinelli J, Harrington A, et al. Functional status at discharge and 30-day readmission risk in COPD. Respir Med 2015; 109: 238-246.

23 Pitta F, Troosters T, Probst VS, et al. Physical activity and hospitalization for exacerbation of COPD. Chest 2006 129: 536-544.

24 Marengoni A, Vetrano DL, Manes-Gravina E, et al. The relationship between COPD and frailty: a systematic review and meta-analysis of observational studies. Chest 2018; 154: 21-40.

25 Fried LP, Tangen CM, Walston J, et al. Frailty in older adults: evidence for a phenotype. J Gerontol A Biol Sci Med Sci 2001; 56: M146-M156.

26 Kon SSC, Jones SE, Schofield SJ, et al. Gait speed and readmission following hospitalisation for acute exacerbations of COPD: a prospective study. Thorax 2015; 70: 1131-1137.

27 Bernabeu-Mora R, García-Guillamón G, Valera-Novella E, et al. Frailty is a predictive factor of readmission within 90 days of hospitalization for acute exacerbations of chronic obstructive pulmonary disease: a longitudina study. Ther Adv Respir Dis 2017; 11: 383-392.

28 Greening NJ, Harvey-Dunstan TC, Chaplin EJ, et al. Bedside assessment of quadriceps muscle by ultrasound after admission for acute exacerbations of chronic respiratory disease. Am J Respir Crit Care Med 2015; 192: 810-816.

29 Global Initiative for Chronic Obstructive Lung Disease (GOLD). Global Strategy for the Diagnosis, Management and Prevention of COPD. 2019. Available from: http://goldcopd.org/

30 Tsoumakidou M, Tzanakis N, Voulgaraki O, et al. Is there any correlation between the ATS, BTS, ERS and GOLD COPD's severity scales and the frequency of hospital admissions? Respir Med 2004; 98: 178-183.

31 Gudmundsson G, Gislason T, Janson C, et al. Risk factors for rehospitalisation in COPD: role of health status anxiety and depression. Eur Respir J 2005; 26: 414-419. 
Cao Z, Ong K, Eng P, et al. Frequent hospital readmissions for acute exacerbation of COPD and their associated factors. Respirology 2006; 11: 188-195.

Wang Q, Bourbeau J. Outcomes and health-related quality of life following hospitalization for an acute exacerbation of COPD. Respirology 2005; 10: 334-340.

de Miguel-Díez J, Jiménez-García R, Hernández-Barrera V, et al. Readmissions following an initial hospitalization by COPD exacerbation in Spain from 2006 to 2012. Respirology 2016; 21: 489-496.

Pouw EM, Ten Velde GP, Croonen BH, et al. Early non-elective readmission for chronic obstructive pulmonary disease is associated with weight loss. Clin Nutr 2000; 19: 95-99.

Hunter LC, Lee RJ, Butcher I, et al. Patient characteristics associated with risk of first hospital admission and readmission for acute exacerbation of chronic obstructive pulmonary disease (COPD) following primary care COPD diagnosis: a cohort study using linked electronic patient records. BMJ Open 2016; 6: e009121.

Vermeeren MA, Schols AM, Wouters EF. Effects of an acute exacerbation on nutritional and metabolic profile of patients with COPD. Eur Respir J 1997; 10: 2264-2269.

Gershon AS, Dolmage TE, Stephenson A, et al. Chronic obstructive pulmonary disease and socioeconomic status: a systematic review. COPD 2012; 9: 216-226.

Keating A, Lee A, Holland AE. What prevents people with chronic obstructive pulmonary disease from attending pulmonary rehabilitation? A systematic review. Chron Respir Dis 2011; 8: 89-99.

Steer J, Gibson J, Bourke SC. The DECAF score: predicting hospital mortality in exacerbations of chronic obstructive pulmonary disease. Thorax 2012; 67: 970-976.

Chu CM, Chan VL, Lin AWN, et al. Readmission rates and life threatening events in COPD survivors treated with non-invasive ventilation for acute hypercapnic respiratory failure. Thorax 2004; 59: 1020-1025.

Confalonieri M, Garuti G, Cattaruzza MS, et al. A chart of failure risk for noninvasive ventilation in patients with COPD exacerbation. Eur Respir J 2005; 25: 348-355.

Lun CT, Chan VL, Leung WS, et al. A pilot randomized study comparing two methods of non-invasive ventilation withdrawal after acute respiratory failure in chronic obstructive pulmonary disease. Respirology 2013; 18: 814-819.

Sellares J, Ferrer M, Anton A, et al. Discontinuing noninvasive ventilation in severe chronic obstructive pulmonary disease exacerbations: a randomised controlled trial. Eur Respir J 2017; 50: 1601448.

Wilkinson TMA, Donaldson GC, Hurst JR, et al. Early therapy improves outcomes of exacerbations of chronic obstructive pulmonary disease. Am J Respir Crit Care Med 2004; 169: 1298-1303.

Donaldson GC, Seemungal TAR, Bhowmik A, et al. Relationship between exacerbation frequency and lung function decline in chronic obstructive pulmonary disease. Thorax 2002; 57: 847-852.

Hurst J, Vestbo J, Anzueto A, et al. Susceptibility to exacerbation in chronic obstructive pulmonary disease. N Engl J Med 2010; 363: 1128-1138.

Perera WR, Hurst JR, Wilkinson TMA, et al. Inflammatory changes, recovery and recurrence at COPD exacerbation. Eur Respir J 2007; 29: 527-534.

Duman D, Aksoy E, Agca MC, et al. The utility of inflammatory markers to predict readmissions and mortality in COPD cases with or without eosinophilia. Int J Chron Obstruct Pulmon Dis 2015; 10: 2469-2478.

Vermeersch K, Belmans A, Bogaerts K, et al. Treatment failure and hospital readmissions in severe COPD exacerbations treated with azithromycin versus placebo - a post-hoc analysis of the BACE randomized controlled trial. Respir Res 2019; 20: 237.

Hurst JR, Donaldson GC, Wilkinson TMA, et al. Epidemiological relationships between the common cold an exacerbation frequency in COPD. Eur Respir J 2005; 26: 846-852.

Hewitt R, Farne H, Ritchie A, et al. The role of viral infections in exacerbations of chronic obstructive pulmonary disease and asthma. Ther Adv Respir Dis 2016; 10: 158-174. pulmonary disease increases the risk of readmission. Respirology 2013; 18: 996-1002.

Bekkat-Berkani R, Wilkinson T, Buchy $\mathrm{P}$, et al. Seasonal influenza vaccination in patients with COPD: a systematic literature review. BMC Pulm Med 2017; 17: 79. Insights for therapeutic strategies. Am J Respir Crit Care Med 2020; 201: 83-94.

Cabello $\mathrm{H}$, Torres A, Celis R, et al. Bacterial colonization of distal airways in healthy subjects and chronic lung disease: a bronchoscopic study. Eur Respir J 1997; 10: 1137-1144.

Patel IS, Seemungal TAR, Wilks M, et al. Relationship between bacterial colonisation and the frequency, character, and severity of COPD exacerbations. Thorax 2002; 57: 759-764.

Mayhew D, Devos N, Lambert C, et al. Longitudinal profiling of the lung microbiome in the AERIS study demonstrates repeatability of bacterial and eosinophilic COPD exacerbations. Thorax 2018; 73: 422-430.

Umetsu D, Ambrosino D, Quinti I, et al. Recurrent sinopulmonary infection and impaired antibody response to bacterial capsular polysaccharide antigen in children with selective IgG-subclass deficiency. N Engl J Med 1985; 313: 1247-1251.

Popa V, Kim K, Heiner D. IgG deficiency in adults with recurrent respiratory infections. Ann Allergy 1993; 70: 418-424.

Leitao Filho FS, Ra SW, Mattman A, et al. Serum IgG subclass levels and risk of exacerbations and hospitalizations in patients with COPD. Respir Res 2018; 19: 30 .

Leitao Filho FSS, Mattman A, Schellenberg R, et al. Hypogammaglobulinemia as a predictor of hospitalizations in COPD: a meta-analysis. Am J Respir Crit Care Med 2019; 199: A3999.

Rutgers SR, Timens W, Kaufmann HF, et al. Comparison of induced sputum with bronchial wash, bronchoalveolar lavage and bronchial biopsies in COPD. Eur Respir J 2000; 15: 109-115.

Couillard S, Larivée P, Courteau J, et al. Eosinophils in COPD exacerbations are associated with increased readmissions. Chest 2017; 151: 366-373.

Bélanger M, Couillard S, Courteau J, et al. Eosinophil counts in first COPD hospitalizations: a comparison of health service utilization. Int J Chron Obstruct Pulmon Dis 2018; 13: 3045-3054.

Barnes NC, Sharma R, Lettis S, et al. Blood eosinophils as a marker of response to inhaled corticosteroids in COPD. Eur Respir J 2016; 47: 1374-1382. 
Pascoe S, Locantore N, Dransfield M, et al. Blood eosinophil counts, exacerbations, and response to the addition of inhaled fluticasone furoate to vilanterol in patients with chronic obstructive pulmonary disease: a secondary analysis of data from two parallel randomised controlled trials. Lancet Respir Med 2015; 3: 435-442.

68 Puhan MA, Garcia-Aymerich J, Frey M, et al. Expansion of the prognostic assessment of patients with chronic obstructive pulmonary disease: the updated BODE index and the ADO index. Lancet 2009; 374: 704-711.

69 Soler-Cataluña JJ, Martínez-García MÁ, Sánchez LS, et al. Severe exacerbations and BODE index: two independent risk factors for death in male COPD patients. Respir Med 2009; 103: 692-699.

70 Jones RC, Donaldson GC, Chavannes NH, et al. Derivation and validation of a composite index of severity in chronic obstructive pulmonary disease: the DOSE index. Am J Respir Crit Care Med 2009; 180: 1189-1195.

71 van Walraven C, Dhalla IA, Bell C, et al. Derivation and validation of an index to predict early death or unplanned readmission after discharge from hospital to the community. CMAJ 2010; 182: 551-557.

72 Echevarria C, Steer J, Heslop-Marshall K, et al. The PEARL score predicts 90-day readmission or death after hospitalisation for acute exacerbation of COPD. Thorax 2017; 72: 686-693.

73 Hakim MA, Garden FL, Jennings MD, et al. Performance of the LACE index to predict 30-day hospital readmissions in patients with chronic obstructive pulmonary disease. Clin Epidemiol 2018; 10: 51-59.

74 Ostridge K, Wilkinson TMA. Present and future utility of computed tomography scanning in the assessment and management of COPD. Eur Respir J 2016; 48: 216-228.

75 Rothberg MB, Pekow PS, Lahti M, et al. Antibiotic therapy and treatment failure in patients hospitalized for acute exacerbations of chronic obstructive pulmonary disease. JAMA 2019; 303: 2035-2042.

76 Stefan MS, Rothberg MB, Shieh MS, et al. Association between antibiotic treatment and outcomes in patients hospitalized with acute exacerbation of COPD treated with systemic steroids. Chest 2013; 143: 82-90.

77 Vermeersch K, Gabrovska M, Aumann J, et al. Azithromycin During Acute Chronic Obstructive Pulmonary Disease Exacerbations Requiring Hospitalization (BACE): a multicenter, randomized, double-blind, placebo-controlled trial. Am J Respir Crit Care Med 2019; 200: 857-868.

78 Menzel M, Akbarshahi H, Bjermer L, et al. Azithromycin induces anti-viral effects in cultured bronchial epithelial cells from COPD patients. Sci Rep 2016; 6: 28698.

79 Bafadhel M, McKenna S, Terry S, et al. Acute exacerbations of chronic obstructive pulmonary disease: identification of biologic clusters and their biomarkers. Am J Respir Crit Care Med 2011; 184: 662-671.

80 Walters J, Tan D, White C, et al. Systemic corticosteroids for acute exacerbations of chronic obstructive pulmonary disease. Cochrane Database Syst Rev 2014; 9: CD001288.

81 Walters JA, Wang W, Morley C, et al. Different durations of corticosteroid therapy for exacerbations of chronic obstructive pulmonary disease. Cochrane Database Syst Rev 2011; 10: CD006897.

82 Leuppi J, Schuetz P, Bingisser R, et al. Short-term vs conventional glucocorticoid therapy in acute exacerbations of chronic obstructive pulmonary disease: the REDUCE randomized clinical trial. JAMA 2013; 309: 2223-2231.

83 Bafadhel M, McKenna S, Terry S, et al. Blood eosinophils to direct corticosteroid treatment of exacerbations of chronic obstructive pulmonary disease: a randomized placebo-controlled trial. Am J Respir Crit Care Med 2012; 186: $48-55$.

84 Sin DD, Tu JV. Inhaled corticosteroids and the risk of mortality and readmission in elderly patients with chronic obstructive pulmonary disease. Am J Respir Crit Care Med 2001; 164: 580-584.

85 Crim C, Calverley PMA, Anderson JA, et al. Pneumonia risk in COPD patients receiving inhaled corticosteroids alone or in combination: TORCH study results. Eur Respir J 2009; 34: 641-647.

86 Soriano JB, Kiri VA, Pride NB, et al. Inhaled corticosteroids with/without long-acting $\beta$-agonists reduce the risk of rehospitalization and death in COPD patients. Am J Respir Med 2003; 2: 67-74.

87 Tran M, Xiang P, Rascati KL, et al. Predictors of appropriate pharmacotherapy management of COPD exacerbations and impact on 6-month readmission. J Manag Care Spec Pharm 2016; 22: 1186-1193.

88 Vestbo J, Anderson JA, Calverley PMA, et al. Adherence to inhaled therapy, mortality and hospital admission in COPD. Thorax 2009; 64: 939-943.

89 Blee J, Roux RK, Gautreaux S, et al. Dispensing inhalers to patients with chronic obstructive pulmonary disease on hospital discharge: effects on prescription filling and readmission. Am J Health Syst Pharm 2015; 72: 1204-1208.

90 Toy EL, Beaulieu NU, McHale JM, et al. Treatment of COPD: relationships between daily dosing frequency, adherence, resource use, and costs. Respir Med 2011; 105: 435-441.

91 Rinne ST, Castaneda J, Lindenauer PK, et al. Chronic obstructive pulmonary disease readmissions and other measures of hospital quality. Am J Respir Crit Care Med 2017; 196: 47-55.

92 Säynäjäkangas $\mathrm{O}$, Kinnunen $\mathrm{T}$, Tuuponen $\mathrm{T}$, et al. Length of stay and interval to readmission in emergency hospital treatment of COPD. Age Ageing 2004; 33: 567-570.

93 Nguyen HQ, Chu L, Amy Liu IL, et al. Associations between physical activity and 30-day readmission risk in chronic obstructive pulmonary disease. Ann Am Thorac Soc 2014; 11: 695-705.

94 Neder JA, Sword D, Ward SA, et al. Home based neuromuscular electrical stimulation as a new rehabilitative strategy for severely disabled patients with chronic obstructive pulmonary disease (COPD). Thorax 2002; 57: 333-337.

95 Nápolis LM, Dal Corso S, Neder JA, et al. Neuromuscular electrical stimulation improves exercise tolerance in chronic obstructive pulmonary disease patients with better preserved fat-free mass. Clinics 2011; 66: 401-406.

96 Spruit MA, Singh SJ, Garvey C, et al. An official American Thoracic Society/ European Respiratory Society statement: key concepts and advances in pulmonary rehabilitation. Am J Respir Crit Care Med 2013; 188: e13-e64.

97 Puhan M, Scharplatz M, Troosters $\mathrm{T}$, et al. Pulmonary rehabilitation following exacerbations of chronic obstructive pulmonary disease. Cochrane Database Syst Rev 2016: 12: CD005305.

98 Greening NJ, Williams JEA, Hussain SF, et al. An early rehabilitation intervention to enhance recovery during hospital admission for an exacerbation of chronic respiratory disease: randomised controlled trial. BMJ 2014; 349: g4315.

99 Bourne S, DeVos R, North M, et al. Online versus face-to-face pulmonary rehabilitation for patients with chronic obstructive pulmonary disease: randomised controlled trial. BMJ Open 2017; 7: e014580. 
100 Ferreira IM, Brooks D, White J, et al. Nutritional supplementation for stable chronic obstructive pulmonary disease. Cochrane Database Syst Rev 2012; 12: CD000998.

101 Snider JT, Jena AB, Linthicum MT, et al. Effect of hospital use of oral nutritional supplementation on length of stay, hospital cost, and 30-day readmissions among Medicare patients with COPD. Chest 2015; 147: 1477-1484.

102 van de Bool C, Rutten EPA, van Helvoort A, et al. A randomized clinical trial investigating the efficacy of targeted nutrition as adjunct to exercise training in COPD. J Cachexia Sarcopenia Muscle 2017; 8: 748-758.

103 Murphy PB, Rehal S, Arbane G, et al. Effect of home noninvasive ventilation with oxygen therapy vs oxygen therapy alone on hospital readmission or death after an acute COPD exacerbation: a randomized clinical trial. JAMA 2017; 317: 2177-2186.

104 Lellouche F, Bouchard PA, Roberge M, et al. Automated oxygen titration and weaning with FreeO2 in patients with acute exacerbation of COPD: a pilot randomized trial. Int J Chron Obstruct Pulmon Dis 2016; 11: 1983-1990.

105 Plant PK, Owen JL, Elliott MW. One year period prevalence study of respiratory acidosis in acute exacerbations of COPD: implications for the provision of non-invasive ventilation and oxygen administration. Thorax 2000; 55: 550-554.

106 Eaton T, Fergusson W, Kolbe J, et al. Short-burst oxygen therapy for COPD patients: a 6-month randomised controlled study. Eur Respir J 2006; 27: 697-704.

107 Hardinge M, Suntharalingam J, Wilkinson T. Guideline update: The British Thoracic Society Guidelines on home oxygen use in adults. Thorax 2015; 70: 589-591.

108 Cranston JM, Crockett A, Moss J, et al. Domiciliary oxygen for chronic obstructive pulmonary disease. Cochrane Database Syst Rev 2005; 4: CD001744.

109 Ringbaek TJ, Fabricius P, Lange P. The effect of home oxygen therapy on hospitalization in moderate hypoxaemic COPD. Chron Respir Dis 2005; 2: 107-108.

110 Ringbaek TJ, Viskum K, Lange P. Does long-term oxygen therapy reduce hospitalisation in hypoxaemic chronic obstructive pulmonary disease? Eur Respir J 2002; 20: 38-42.

111 Clini E, Vitacca M, Foglio K, et al. Long-term home care programmes may reduce hospital admissions in COPD with chronic hypercapnia. Eur Respir J 1996; 9: 1605-1610.

112 Maddocks M, Lovell N, Booth S, et al. Palliative care and management of troublesome symptoms for people with chronic obstructive pulmonary disease. Lancet 2017; 390: 988-1002.

113 Brian Cassel J, Kerr KM, McClish DK, et al. Effect of a home-based palliative care program on healthcare use and costs. J Am Geriatr Soc 2016; 64: 2288-2295.

114 Duenk RG, Verhagen C, Bronkhorst EM, et al. Proactive palliative care for patients with COPD (PROLONG) a pragmatic cluster controlled trial. Int J Chron Obstruct Pulmon Dis 2017; 12: 2795-2806.

115 Tavares N, Jarrett N, Hunt K, et al. Palliative and end-of-life care conversations in COPD: a systematic literature review. ERJ Open Res 2017; 3: 00068-2016.

116 Schulman-Green D, Jaser S, Martin F, et al. Processes of self-management in chronic illness. J Nurs Scholarsh 2012; 44: 136-144

117 Effing T, Monninkhof EM, van der Valk PD, et al. Self-management education for patients with chronic obstructive pulmonary disease. Cochrane Database Syst Rev 2007: CD002990.

118 Benzo R, Vickers K, Novotny PJ, et al. Health coaching and chronic obstructive pulmonary disease rehospitalization: a randomized study. Am J Respir Crit Care Med 2016; 194: 672-680.

119 Rice KL, Dewan N, Bloomfield HE, et al. Disease management program for chronic obstructive pulmonary disease: a randomized controlled trial. Am J Respir Crit Care Med 2010; 182: 890-896.

120 Bourbeau J, Julien M, Maltais F, et al. Reduction of hospital utilization in patients with chronic obstructive pulmonary disease: a disease-specific self-management intervention. Arch Intern Med 2003; 163: 585-591.

121 Collinsworth AW, Brown RM, James CS, et al. The impact of patient education and shared decision making on hospital readmissions for COPD. Int J Chron Obstruct Pulmon Dis 2018; 13: 1325-1332.

122 Aboumatar H, Naqibuddin M, Chung S, et al. Effect of a hospital-initiated program combining transitional care and long-term self-management support on outcomes of patients hospitalized with chronic obstructive pulmonary disease: a randomized clinical trial. JAMA 2019; 322: 1371-1380.

123 Disler RT, Gallagher RD, Davidson PM. Factors influencing self-management in chronic obstructive pulmonary disease: an integrative review. Int J Nurs Stud 2012; 49: 230-242.

124 Ospina MB, Mrklas K, Deuchar L, et al. A systematic review of the effectiveness of discharge care bundles for patients with COPD. Thorax 2017; 72: 31-39.

125 Turner AM, Lim WS, Rodrigo C, et al. A care-bundles approach to improving standard of care in AECOPD admissions: results of a national project. Thorax 2015; 70: 992-994.

126 Ohar JA, Loh $\mathrm{CH}$, Lenoir $\mathrm{KM}$, et al. A comprehensive care plan that reduces readmissions after acute exacerbations of COPD. Respir Med 2018; 141: 20-25.

127 Morton K, MacNeill S, Sanderson E, et al. Evaluation of 'care bundles' for patients with chronic obstructive pulmonary disease (COPD): a multisite study in the UK. BMJ Open Respir Res 2019; 6: e000425.

128 Zafar MA, Panos RJ, Ko J, et al. Reliable adherence to a COPD care bundle mitigates system-level failures and reduces COPD readmissions: a system redesign using improvement science. BMJ Qual Saf 2017; 26: 908-918.

129 Hernandez C, Casas A, Escarrabill J, et al. Home hospitalisation of exacerbated chronic obstructive pulmonary disease patients. Eur Respir J 2003; 21: 58-67.

130 Jeppesen E, Brurberg KG, Vist GE, et al. Hospital at home for acute exacerbations of chronic obstructive pulmonary disease. Cochrane Database Syst Rev 2012; 5: CD003573. 